\title{
Sugar Alcohols: What Is the Evidence for Caries-Preventive and Caries-Therapeutic Effects?
}

\author{
C. van Loveren \\ Department of Cariology/Endodontology/Pedodontology, Academic Centre for Dentistry Amsterdam, \\ Amsterdam, The Netherlands
}

\section{Key Words}

Sugar alcohols · Xylitol · Sorbitol · Dental caries ·

Preventive effect $\cdot$ Therapeutic effect

\begin{abstract}
The most widely used sugar alcohols are: xylitol, sorbitol, mannitol, maltitol, lactitol and the products Lycasin ${ }^{\circledR}$ and Palatinit ${ }^{\circledR}$. It is often claimed that xylitol is superior to the other sugar alcohols for caries control. This paper examines clinical studies on the caries-preventive and therapeutic effects of sugar alcohols with emphasis on sorbitol and xylitol. It is concluded that chewing sugarfree gum 3 or more times daily for prolonged periods of time may reduce caries incidence irrespective of the type of sugar alcohol used. It may be sufficient to do this only on school days. Sucking xylitol-containing candies or tablets may have a similar effect as chewing xylitol chewing gum. Clinical trials suggest greater caries reductions from chewing gums sweetened with xylitol than from gums sweetened with sorbitol. However, the superiority of xylitol was not confirmed in 2 out of 4 clinical trials comparing the caries-preventive effect of xylitol- with sorbitol-sweetened gums. The caries-preventive effects of polyol-containing gums and candies seem to be based on stimulation of the salivary flow,
\end{abstract}

\section{KARGER}

Fax +41613061234

E-Mail karger@karger.ch

www.karger.com
(C) 2004 S. Karger AG, Basel

0008-6568/04/0383-0286\$21.00/0

Accessible online at: www. karger.com/cre although an antimicrobial effect cannot be excluded. There is no evidence for a caries-therapeutic effect of xylitol. These conclusions are in line with those of recent reviews and with the conclusions of the Scientific Committee on Medicinal Products and Medical Devices of the EU Commission.

Copyright $@ 2004$ S. Karger AG, Basel

The most widely used sugar alcohols are: xylitol (a pentitol), sorbitol, mannitol (both hexitols), maltitol, lactitol (both 12-carbon polyols) and the products Lycasin ${ }^{\circledR}(6-$ $8 \%$ sorbitol, 50-55\% maltitol, 20-25\% maltotriitol and 10-20\% polysaccharide alcohols) and Palatinit ${ }^{\circledR}(1: 1$ mixture of two 12-carbon polyols). Other sugar alcohols such as erythritol are emerging [Kawanabe et al., 1992; Mäkinen et al., 2001]. All sugar alcohols have been tested in vitro for fermentation by oral micro-organisms and can be classified as hypo- or non-acidogenic. There is a reduced or virtually no extracellular polysaccharide production from sugar alcohols. Hypo- and non-acidogenicity of the sugar alcohols are confirmed by plaque $\mathrm{pH}$ measurements. From animal experiments and intra-oral cariogenicity tests, it is concluded that sugar alcohols are (extremely) low or non-cariogenic. In vitro, adaptation of mutans streptococci by frequent subculturing in sorbitol,
C. van Loveren

Department of Cariology/Endodontology/Pedodontology

Academic Centre for Dentistry Amsterdam, Louwesweg 1

NL-1066 EA Amsterdam (The Netherlands)

Tel. +31 205188662 , Fax +31 20 6692881, E-Mail c.van.loveren@acta.nl 
maltitol, lactitol and Lycasin occurs, but this is not likely to be important in vivo when the sugar alcohols are given in combination with a diet rich in sucrose. In all these experiments, xylitol stands out and is widely believed to possess anticaries properties, which may render it superior to the other sugar alcohols for potential caries control [for reviews, see Tanzer, 1995; Trahan, 1995]. With rare exceptions, xylitol is not fermented by oral micro-organisms. Xylitol inhibits the growth of mutans streptococci [Vadeboncoeur et al., 1983] even selectively in mixed chemostat cultures [Bradshaw and Marsh, 1994; Rogers et al., 1991]. It interferes with glycolysis when glucose is used as energy source [Wåler and Rölla, 1983] although this may not be a stable phenomenon in vivo [Scheie et al., 1998]. In vivo there was also no reduction of the acidogenic response of dental plaque to sucrose after periods of using xylitol chewing gums [Wennerholm, et al., 1994] or xylitol mouth rinses [Lingström et al., 1997]. It has been proposed that xylitol weakens the caries-inductive properties of dental plaque colonizing newly erupting tooth surfaces [Isokangas et al., 1993] and that such a caries-protective effect might persist several years after the cessation of use of xylitol products [Hujoel et al., 1999]. From animal experiments, it has been concluded that xylitol is anticariogenic [Havenaar et al., 1984].

The interesting biological properties of sugar alcohols, xylitol in particular, have prompted researchers to explore the clinical effects of these compounds. There is no doubt that substitution of sucrose with polyols in chewing gums and lozenges has a caries-preventive effect. However, a number of claims may not be so well supported. In this paper, the caries-preventive and caries-therapeutic effects of xylitol will be discussed and, where appropriate, compared to those of sorbitol. The present paper does not intend to review exhaustively all aspects of xylitol or any other sugar alcohol.

\section{Effects on Dental Plaque}

Xylitol in chewing gum may reduce the amount of dental plaque [Topitsoglou et al., 1983; Söderling et al., 1989; Mäkinen et al., 1989]. Some studies, however, suggest that sorbitol might be as effective [Wennerholm et al., 1994; Söderling et al., 1989; Birkhed et al., 1979]. Moreover the quantitative effect - a reduction of $10-20 \%$ in plaque index - should not be overemphasized from a cariological point of view [Birkhed, 1994].

An interesting effect of xylitol is its ability to reduce the population of mutans streptococci in plaque [Isokangas et al., 1991; Mäkinen et al., 1989] and to loosen the plaque and mutans streptococci binding to the tooth surfaces [Söderling et al., 1991]. This effect was found to depend on the frequency of chewing and the initial level of mutans streptococci [Mäkinen et al., 1989] and seemed to persist after the habitual use of xylitol had stopped [Isokangas et al., 1991]. However, a 3-month experiment in which 2 lozenges were sucked (in total $4 \mathrm{~g}$ of xylitol) 4 times daily showed no reduction of the numbers of mutans streptococci in dental plaque [Birkhed et al., 1979]. Tenovuo et al. [1997] did not find a reduction of the numbers of salivary mutans streptococci after 1 month's regular use of 3 xylitol lozenges a day. After a 2-week experiment, the numbers of mutans streptococci were not significantly different in plaque or saliva whether either a xylitol $(65 \%$ $\mathrm{w} / \mathrm{w})$, xylitol-sorbitol (37.5\% xylitol and 37.5\% sorbitol $\mathrm{w} / \mathrm{w}$ ) or unsweetened chewing gum base was chewed 3-5 times a day for approximately $3 \mathrm{~min}$ each time [Söderling et al., 1997]. After a period of approximately 4 weeks, no differences were observed in numbers of mutans streptococci in saliva when chewing gum sweetened with $70 \%$ xylitol, $35 \%$ xylitol and $35 \%$ sorbitol or $17.5 \%$ xylitol and $52.5 \%$ sorbitol was chewed for 5 min 12 times daily [Wennerholm et al., 1994]. In contrast, in patients wearing fixed orthodontic appliances 6 times daily use of gums sweetened with xylitol or a xylitol-sorbitol mixture (4:1 or $3: 2$ ) reduced the numbers of mutans streptococci in plaque and saliva [Isotupa et al., 1995]. Reduced salivary numbers of mutans streptococci were also observed after a 3-week period of chewing xylitol gum 3 times a day [Autio, 2002]. Hildebrandt and Sparks [2000] used xylitol gum ( 3 times daily) to maintain a chlorhexidine-borne reduction of salivary mutans streptococci for 3 months.

Wennerholm et al. [1994] showed that when gums were sweetened with $70 \%$ sorbitol, there was a small but statistically significant increase in numbers of mutans streptococci from $5.9 \pm 1.0$ to $6.6 \pm 0.6 \log$ CFU $/ \mathrm{ml}$ saliva. Also Söderling et al. [1989] found an increase in the numbers of mutans streptococci in saliva after the shortterm use of a sorbitol gum. Concomitantly, they found a lower resting $\mathrm{pH}$ in interproximal plaque [Söderling et al., 1989]. Mäkinen et al. [2002] confirmed an increase in the numbers of mutans streptococci in dental plaque after 64 days of use of sorbitol gum 5 times a day. The mutansincreasing effect of sorbitol seems to be counteracted when xylitol is added to the gum [Wennerholm et al., 1994].

In conclusion, the data show that regular use of xylitol is more likely to reduce numbers of mutans streptococci in saliva and plaque than the regular use of sorbitol. How- 
ever, the studies on the effect of xylitol did not all confirm a mutans-reducing effect. Moreover the clinical relevance of these reductions of mutans streptococci remains to be shown.

\section{Adaptation to Xylitol}

Frequent exposure to xylitol may increase the proportions of xylitol-resistant mutans streptococci in the oral cavity [Trahan et al., 1992]. Xylitol-resistant mutans streptococci are lacking the fructose phosphotransferase system responsible for xylitol uptake. So, this adaptation does not imply a risk of acid formation from xylitol but merely minimizes the antimicrobial effects of xylitol. Cariogenic traits of xylitol-resistant mutans streptococci have not been shown to be different from those of xylitol-sensitive strains [Assev et al., 2002; Beckers, 1988]. Moreover, in rat experiments the caries reduction due to the consumption of xylitol was independent of whether the animals were superinfected with the xylitol-resistant or the wild-type strain [Beckers, 1988].

Trahan et al. [1992] observed that the proportion of xylitol-resistant mutans streptococci did not increase in dental plaque but did so in saliva. The explanation frequently offered for this observation is that xylitol-resistant or xylitol-adapted strains shed more easily from the tooth surface than xylitol-sensitive strains. Subsequently, this explanation is often used to explain reduced plaque formation and reduced colonization of mutans streptococci following transmission after a period of frequent use of xylitol. However, evidence is lacking to justify this cascade of explanations. There is no direct evidence for a stable decrease in the adhesive properties of mutans streptococci after the use of xylitol.

\section{Clinical Trials with Sugar Alcohols}

Conclusions from clinical trials with chewing gums have in general to be interpreted with caution. Both within and between studies there may be differences that affect the results. There may be differences in socio-economic status of the populations, caries risks, dietary and oral hygiene habits, motivation for oral health and in compliance to the programme. Also the diagnostic criteria may be different or differently interpreted. When study groups are randomized into school classes, the study may not be truly blind. Other confounders such as drop-out rates might be different and have a great effect. Access of the control group to the test products cannot always be controlled. Most of these potential confounders cannot be ruled out and unless identified and controlled for, it is impossible to estimate their effects on the outcome of the study.

\section{Clinical Trials with Sorbitol}

In the first clinical study with sorbitol, children receiving sorbitol tablets developed $48 \%$ less caries than control children that did not get tablets [Slack et al., 1964]. However, frequency of intake and quantity of consumption were not reported. In an early chewing gum study, children that used sorbitol gum 3 times daily had 10\% less caries over a 2-year period compared to control children that got no chewing gum [Møller and Poulsen, 1973; Møller, 1977]. A 3-year study in Hungary revealed a 48\% caries reduction in children using chocolate sweetened with sorbitol compared to children eating sucrose-sweetened chocolate [Banoczy et al., 1981]. A test group of 7- to 11year-old children consuming 2 sorbitol gums per day did not develop less caries in a 2-year period than control children not receiving gums [Glass, 1983]. The effect of chewing sorbitol gums 3 times daily after meals at school was only small compared to no gum chewing [Beiswanger et al., 1998]. The effect was $8 \%$ in the total group and $11 \%$ for the children at high risk for caries. No significant caries reductions were observed of 3 nor of 5 times daily chewing at school of a gum sweetened with $55.5 \%$ sorbitol and $4.3 \%$ xylitol and containing $2 \%$ carbamide compared to no gum chewing at school [Petersen and Razanamihaja, 1999]. A recent 3-year-study performed at schools in Lithuania showed no statistically significant reduction in the increment of cavitated lesions after the use of two types of sorbitol gums compared to when no gums were delivered at schools [Machiulskiene et al., 2001]. When non-cavitated lesions were included in the results, a significant $27 \%$ reduction was found for one of the sorbitol gums tested. The other sorbitol gum was not effective. In another study, an approximately 38\% caries reduction (33\% when white spot lesions were included in the analysis) was observed in children that were instructed to use sorbitol gum (65\% sorbitol and mannitol) after breakfast (supervised at school), lunch (supervised at school) and evening meal (unsupervised at home) compared to a group that chewed no gums after meals [Szöke et al., 2001]. A 40-month study designed to measure the relative effects of chewing gums sweetened with sorbitol alone, sorbitol/xylitol mixtures and xylitol alone (Belize study) 
showed that originally 10 -year-old children chewing sorbitol pellet gums 5 times daily developed $26 \%$ fewer caries lesions compared to no-gum chewers and $37 \%$ compared to children using sugared chewing gum [Mäkinen et al., 1995a]. In 6-year-old children, chewing sorbitol pellet gum resulted in a $55 \%$ decrease in the caries increment in the primary dentition when the children were compared to no-gum users after the 2-year evaluation period [Mäkinen et al., 1996a]. When sorbitol stick gums were chewed, the reduction was 30\%.

In conclusion, most clinical trials with sorbitol-sweetened gums indicate that between- or after-meal consumption of sorbitol-sweetened chewing gum has a cariespreventive effect in comparison with controls without gum use. The effectiveness may vary between 0 and $30 \%$ for the permanent dentition. Chewing sorbitol gum may also be effective in the prevention of caries in the primary dentition. But because of the limited number of studies, it is impossible to quantify this effect.

\section{Clinical Trials with Xylitol}

In the first clinical xylitol study, the Turku sugar study, dietary sucrose was almost completely replaced by xylitol. After 2 years, the sucrose group had developed 7.2 new DMFS and the xylitol group 0 [Scheinin et al., 1975b]. In a parallel 1-year chewing gum study, the group receiving a sucrose-sweetened gum developed approximately 3 new DMFS, while in the xylitol group (chewing gums sweetened with 50\% xylitol and 6\% sorbitol) the number of DMFS decreased by 1 DMFS [Scheinin et al., 1975a]. A collaborative WHO field study in Hungary showed a caries-preventive effect in a group of children using xylitol in gums, chocolate and other confectionery daily [Scheinin et al., 1985]. This xylitol group developed 35\% less caries than a fluoride control group and $45 \%$ less than a nonfluoride, non-xylitol control group. Because of the different daily exposures to fluoride in the 3 groups, it was not clear to what extent the effect could be attributed to the xylitol consumption. Another series of collaborative WHO studies in Thailand and French Polynesia compared fluoride chewing gums sweetened with a mixture of xylitol and sorbitol or sweetened with sucrose with fortnightly fluoride rinsing $(0.2 \% \mathrm{NaF})$ [Khambanonda et al., 1983; Barmes et al., 1985]. The results from these studies are conflicting. While one found the fluoride rinsing to be effective, the other did not. Since the experimental designs were not very well controlled, the scientific value of these studies can be questioned.

Sugar Alcohols and Dental Caries
The effects of chewing gums sweetened with $65 \%$ xylitol or with a mixture of $15 \%$ xylitol and $50 \%$ sorbitol, respectively, were compared with a non-gum group in children of low socio-economic status with a high caries rate [Kandelman and Gagnon, 1990]. The two experimental groups had a DMFS increment of 2.24 surfaces, compared with 6.06 surfaces for the control group. In Finland, the Ylievska studies evaluated the effect of chewing frequency: $\leq 1.5$ pieces of xylitol gum a day, 1.5-2.5 pieces or 3 pieces [Isokangas et al., 1988]. All gums were sweetened with xylitol. After 2 years, the DMFS increment in the $\leq 1.5$ gum group was not different from the no-gum control group, in the 1.5- to 2.5-pieces group there was a non-significant difference of approximately 30\% while in the 3-pieces group the reduction was significant at approximately 55-60\%. The Belize study [Mäkinen et al., 1995a] studied the effect of mixtures of sweeteners compared to a no-gum group and a sucrose gum group. Experimental gums were pellet gums sweetened with xylitol or mixtures of xylitol and sorbitol in the ratios 3:2 and $1: 3$ and gum sticks sweetened with xylitol as the only sweetener. The xylitol gums were chewed either 3 or 5 times a day and the mixtures 5 times a day. The children chewing xylitol pellet gums 5 or 3 times a day developed 73 and 59\% fewer caries lesions, respectively, than the nogum chewers. For the xylitol stick gum chewers, these values were 56 and $52 \%$, respectively. The caries reduction was lower when the mixtures were chewed $(51 \%$ for the $1: 3$ mixture and $44 \%$ for the 3:2 mixture), but the differences were only statistically significant compared with the group using 5 xylitol gum pellets. In a field study in Estonia, the effect of the use of a chewing gum with $65 \%$ xylitol 3 times a day for 10 min supervised at school days was compared to the consumption of candies sweetened with $49 \%$ xylitol supplemented with maltitol or polydextrose with the same intensity and a non-gum control group [Alanen et al., 2000]. After 3 years, both xylitol groups showed a significant $35-60 \%$ reduction in caries increment. There were no statistically significant differences between the experimental groups. A recent 3-year-study in Lithuania showed a 36\% reduction in the increment of cavitated lesions $(30 \%$, when non-cavitated lesions were included) when children were instructed to use a xylitol gum 5 times a day [Machiulskiene et al., 2001].

In conclusion, there is a considerable amount of evidence that the use of gum or sweets sweetened with xylitol or a mixture of xylitol and sorbitol prevents dental caries when used several times daily. Compared to controls without gum use the effectiveness varied between 30 and $60 \%$.

Caries Res 2004;38:286-293 


\section{Clinical Trials Comparing the Effects of Chewing Xylitol or Sorbitol Gum}

Up till now only 4 clinical trials have attempted to compare the caries-preventive effect of xylitol and sorbitol in the same setting. The results of these studies are equivocal. In the Belize study [Mäkinen et al., 1995a], the lowest caries onsets varying from 4.6 to 7.8 lesions per 1,000 surfaces per year were observed among initially 10 year-old children that chewed xylitol pellet gums 5 times daily or xylitol sticks 3 times daily. Those children who chewed 5 sorbitol pellets a day developed 12.6 caries lesions per 1,000 surfaces per year. These results indicate that xylitol is superior to sorbitol in reducing the risk of caries onset. The difference should, however, be interpreted with caution. An important confounder may be the drop-out rate, which was as low as $7 \%$ in the sorbitol group, but 24 and $49 \%$ in the xylitol groups, respectively. For 6-year-olds in the Belize study [Mäkinen et al., 1996a], the caries increments in the primary dentition were not statistically significantly different between the xylitol and sorbitol gum chewers. The caries risks for a primary tooth surface in the xylitol pellet and sorbitol pellet gum groups were 1.8 and $2.2 \%$ per year, respectively, while in the no-gum group $5 \%$ of the primary tooth surfaces developed caries. When the children used gum sticks sweetened with either xylitol or sorbitol, 2.4 and 3.7\%, respectively, of the primary tooth surface developed caries within 1 year. Hence, the pellet gums tended to perform better than the stick gums. The study groups were not completely homogeneous with regard to socio-economic factors; furthermore, the xylitol pellet gum group comprised less than half the number of children as did the other groups.

In the Lithuanian chewing gum study with 9- to14year-old children, the xylitol gum group (mean 3-year caries increment 8.1 DMFS) did not perform statistically significantly better than the sorbitol gum group (mean 3-year caries increment 9.0 DMFS) [Machiulskiene et al., 2001]. In this study, the children in the xylitol group were slightly younger and had fewer surfaces present than children in the sorbitol group at the start of the experiment. However, the statistical analyses were adjusted for the effects of age, gender, number of erupted surfaces and baseline DMFS values.

In elderly individuals the effect of polyol sweetened gum and dragées on root surface caries was studied in two small groups of approximately 40 individuals each. Approximately $15 \%$ of the subjects used gum, the others used the dragées. In the xylitol group there were 2.6 lesion onsets per 1,000 surfaces a year contrasting with 13.7 onsets in the sorbitol group [Mäkinen et al., 1996b]. Potential confounders of this study were related to the fact that the individuals in the xylitol group were younger than the individuals in the sorbitol group, and the prebaseline root surface caries increment rates were lower in the sorbitol than in the xylitol group.

In conclusion, superiority of xylitol is not supported in 2 out of the 4 studies comparing the caries-preventive effect of xylitol- and sorbitol-sweetened gum directly.

\section{Remineralization}

Remineralization as a result of using sugar alcohols has been suggested, but the evidence from clinical trials is less clear. In the Turku sugar studies, there were 3 groups consuming either a sucrose-, fructose- or xylitol-sweetened diet. In the xylitol group, the mean caries increment over a 2-year period dropped during the last 3-month period from 0.8 to 0 [Scheinin et al., 1975b]. These results were interpreted as evidence of remineralization. However, careful clinical and radiographic examination revealed the same number of reversals from 'caries without a defect' to 'sound' in each diet group. Reversals of more advanced lesions were not observed. In the parallel Turku chewing gum study, a negative increment of 1 surface was observed during 12 months' use of xylitol gum. However, the report of this study did not differentiate between onsets and reversals [Scheinin et al., 1975a]. So it is not clear whether the negative increment was due to an increased number of reversals, a decreased number of onsets or both.

In the Belize chewing gum study with the younger children, 'rehardening' was observed in 10-27\% of the dentinal lesions [Mäkinen et al., 1995b]. The use of xylitol chewing gum 5 times daily tended to be more effective than when the gum was chewed less frequently or when it was sweetened with sorbitol. However, the types of lesions shown in the publication were mostly large open occlusal caries cavities, which are easily subjected to functional attrition and plaque removal. It is likely therefore that the mechanical effect of chewing, and not the sugar alcohol itself, was responsible for these clinical changes.

In an in situ model, Manning et al. [1992] compared the remineralizing effect on preformed caries-like lesions in enamel specimens of chewing 5 times per day gum sweetened with sorbitol or a mixture of sorbitol/xylitol (3:1) after 3 daily meals and 2 sugary snacks. No significant differences were observed between the remineraliz- 
ing effects of the gums, when the specimens were evaluated by transversal microradiography [Manning et al., 1992].

In conclusion, the present state of the art does not support an anticariogenic or caries-therapeutic effect of xylitol.

\section{Chew or Polyol Effect}

To measure the caries-preventive effect of the polyols per se, polyol-sweetened gums should be compared to a control gum that does not contain polyols but is sweetened by a non-acidogenic/non-cariogenic sweetener. Recently it has been shown that such a control gum was as effective as a sorbitol- or xylitol-sweetened gum, indicating that the caries-preventive effect of chewing sugar-free gum is related to the chewing process rather than being an effect of the polyols [Machiulskiene et al., 2001]. The importance of chewing would also explain why gum pellets with a harder texture were more effective in caries prevention than were softer gum sticks as demonstrated in the Belize study [Mäkinen et al., 1995a, 1996a]. Chewing stimulates salivary flow [Rosenhek et al., 1993] as does sucking of lozenges [Tenovuo et al., 1997]. It is therefore not surprising that the caries-preventive effect of candies sweetened with $49 \%$ xylitol with maltitol or polydextrose has been reported to be similar to that of chewing xylitol (65\%) chewing gum [Alanen et al., 2000].

If there were an effect of polyols per se it might become visible when subjects rinsed with a polyol solution. Giertsen et al. [1999] showed, however, no effect of 4 weeks 3 times daily rinsing for $1 \mathrm{~min}$ with a $40 \%$ xylitol solution on salivary flow rate, on the total number of colony-forming units, streptococci or mutans streptococci in saliva, on dental plaque accumulation, gingivitis development or the acidogenic potential of plaque. This study does not exclude a xylitol effect per se, since the results may partly be explained by the fact that the rinsing protocol did not give sufficient substantivity to a xylitol effect.

\section{Amount, Frequency and Timing}

In many of the studies referred to above, the total amount of xylitol was reported, suggesting that a certain amount of xylitol should be consumed to be effective in caries prevention. However, the studies with gums containing different amounts of xylitol do not support this suggestion. For instance, the study of Kandelman and
Gagnon [1990] suggests that as little as $0.9 \mathrm{~g}$ of xylitol in chewing gum was sufficient for caries prevention, while the Ylivieska study suggests that at least $7 \mathrm{~g}$ of xylitol would be necessary [Isokangas et al., 1988]. Also when comparing the mixed xylitol/sorbitol groups in the Belize study those consuming the lowest daily amount of xylitol ( 2 versus $6 \mathrm{~g}$ a day) had the lowest caries onset risk, although the difference was not statistically significant [Mäkinen et al., 1995a].

In most studies on the effects of sugar substitutes, the participants were asked to chew 3-5 pieces of gum a day. In fact, in a study in which the participants were asked to chew 2 sorbitol-containing gums a day, no caries-inhibitory effect was found [Glass, 1983]. In the Ylivieska study, only 3 gums a day gave protection, while $\leq 2.5$ gums did not [Isokangas et al., 1988]. In the Belize study there was no statistically significant difference when the stick gums were chewed 3 or 5 times daily [Mäkinen et al., 1995a]. When chewing xylitol pellet gums, the 5-times chewers demonstrated a lower caries onset risk than the 3-times chewers [Mäkinen et al., 1995a]. So the data suggest that for caries control, gums should at least be used 3 times a day for prolonged periods of time.

In the Belize study, children were re-examined 5 years after the original 2-year clinical trial [Hujoel et al., 1999]. It was very unlikely that the children had used any of the experimental products over that 5-year period, since they were not available within a distance of $180 \mathrm{~km}$. Five years after the experiment, the children still had less caries than the original control children. Closer examination revealed that teeth erupted after the experimental period were better protected in children that had chewed gums sweetened with xylitol or a xylitol/sorbitol mixture compared to children that had chewed sorbitol-sweetened gum. Compared to the no-gum group, the protection was most prominent in the group of children that used the gum with $100 \%$ xylitol. A continued caries-preventive effect after cessation of using xylitol was also observed in the study of Alanen et al. [2000]. These data suggest a prolonged change in the homoeostasis and cariogenicity of dental plaque. It has been speculated that the adhesive properties of mutans streptococci decrease due to the exposure and adaptation to xylitol [Söderling et al., 1987]. This latter mechanism would also explain why children from mothers that use xylitol frequently are less colonized with mutans streptococci than control children [Isokangas et al., 2000; Söderling et al., 2000; Thorild et al., 2003]. However, there is no direct evidence that there is a stable decrease in the adhesive properties of mutans streptococci after the use of xylitol. The results may at least partly be related to an 
increased awareness for dental health as a result of a longterm, intensive, compliance-demanding preventive regimen.

\section{Conclusions}

Regular use of xylitol is more likely to reduce the numbers of mutans streptococci in saliva and plaque than regular use of sorbitol; however, not all studies on the effect of xylitol confirm a mutans-reducing effect. Moreover, the clinical relevance of a reduction of the intra-oral load of mutans streptococci is not clear. Chewing of sugar-free chewing gum 3 or more times daily for prolonged periods of time may reduce caries incidence irrespective of the type of sugar alcohol added. It may be sufficient to do this only on school days. Sucking of xylitol-containing candies or tablets may have a similar effect as chewing xylitol chewing gum. Clinical trials suggest a higher caries-preventive effect of chewing gum sweetened with xylitol than with sorbitol. However, superiority of xylitol was not confirmed in 2 out of 4 clinical trials comparing the cariespreventive effect of xylitol- and sorbitol-sweetened gums. The caries-preventive effects of polyol-containing gums and candies seem to be based on stimulation of the salivary flow, although an antimicrobial effect cannot be excluded. There is no evidence for a minimal therapeutic dose or a caries-therapeutic effect of xylitol. These conclusions are in line with those of previous recent reviews [Imfeld, 1994; Scheie and Fejerskov, 1998] and with the conclusions of the Scientific Committee on Medicinal Products and Medical Devices of the EU Commission [EU Commission, 2003].

\section{References}

Alanen P, Isokangas P, Gutmann K: Xylitol candies in caries prevention: Results of a field study in Estonian children. Community Dent Oral Epidemiol 2000;28:218-224.

Assev S, Stig S, Scheie AA: Cariogenic traits in xylitol-resistant and xylitol-sensitive mutans streptococci. Oral Microbiol Immunol 2002;17:9599.

Autio JT: Effect of xylitol chewing gum on salivary Streptococcus mutans in preschool children. J Dent Child 2002;69:81-86.

Banoczy J, Hadas E, Esztari I, Marosi I, Nemes J: Three-year results with sorbitol in clinical longitudinal experiments. J Int Assoc Dent Child 1981;12:59-63.

Barmes D, Barnaud J, Khambonada S, Sardo Inferri $\mathrm{J}$ : Field trials of preventive regimes in Thailand and French Polynesia. Int Dent J 1985;35: 66-72.

Beckers HJA: Influence of xylitol on growth, establishment and cariogenicity of Streptococcus mutans in dental plaque of rats. Caries Res 1988;22:166-173

Beiswanger BB, Boneta AE, Mau MS, Katz BP, Proskin HM, Stookey GK: The effect of chewing sugar free gum after meals on clinical caries incidence. J Am Dent Assoc 1998;127:16231626.

Birkhed D: Cariologic aspects of xylitol and its use in chewing gum: A review. Acta Odontol Scand 1994:52:116-127.

Birkhed D, Edwardsson S, Ahldén M-L, Frostell G: Effects of 3 months frequent consumption of hydrogenated starch hydrolysate $\left(\right.$ Lycasin $\left.{ }^{\circledR}\right)$, maltitol, sorbitol and xylitol on human dental plaque. Acta Odontol Scand 1979;37:103115.
Bradshaw DJ, Marsh PD: Effect of sugar alcohols on the composition and metabolism of a mixed culture of oral bacteria in a chemostat. Caries Res 1994;28:251-256.

EU Commission: http://europa.eu.int/comm/food/ fs/sc/scmp/out4_en.pdf. Assessed June 2003.

Giertsen E, Emberland H, Scheie AA: Effects of mouth rinses with xylitol and fluoride on dental plaque and saliva. Caries Res 1999;33:2331 .

Glass RL: A two-year clinical trial of sorbitol chewing gum. Caries Res 1983;17:365-368.

Havenaar R, Huis in't Veld JHJ, de Stoppelaar JD, Backer Dirks O: Anti-cariogenic and remineralizing properties of xylitol in combination with sucrose in rats inoculated with Streptococcus mutans. Caries Res 1984;18:269-277.

Hildebrandt GH, Sparks BS: Maintaining streptococci suppression with xylitol chewing gum. J Am Dent Assoc 2000;131:909-916.

Hujoel PP, Mäkinen KK, Bennett CA, Isotupa KP, Isokangas PJ, Allen P, Mäkinen P-L: The optimum time to initiate habitual xylitol gum chewing for obtaining long-term caries prevention. J Dent Res 1999;78:797-803.

Imfeld TN: Clinical caries studies with polyalcohols: A literature review. Schweiz Monatsschr Zahnmed 1994;104:941-945.

Isokangas P, Alanen P, Tiekso J, Mäkinen KK: Xylitol chewing gum in caries prevention: A field study in children. J Am Dent Assoc 1988; 117:315-320.

Isokangas $\mathrm{P}$, Mäkinen KK, Tiekso J, Alanen P: Long-term effect of xylitol chewing gum in the prevention of dental caries: A follow-up 5 years after termination of a preventive program. Caries Res 1993;27:495-498.
Isokangas P, Söderling E, Pienihäkkinen K, Alanen $\mathrm{P}$ : Occurrence of dental decay in children after maternal consumption of xylitol chewing gum, a follow-up from 0 to 5 years of age. J Dent Res 2000;79:1885-1889.

Isokangas P, Tenovuo J, Söderling E, Männisto H, Mäkinen KK: Dental caries and mutans streptococci in the approximal areas of molars affected by habitual use of xylitol chewing gum. Caries Res 1991;25:444-448.

Isotupa KP, Gunn S, Chen C-Y, Lopatin D, Mäkinen KK: Effect of polyol gums on dental plaque in orthodontic patients. Am J Orthod Dentofac Orthop 1995; 107:497-504.

Kandelman D, Gagnon G: A 24-month clinical study of the incidence and progression of dental caries in relation to consumption of chewing gum containing xylitol in school preventive programs. J Dent Res 1990;69:1771-1775.

Kawanabe J, Hirasawa M, Takeuchi T, Oda T, Ikeda T: Noncariogenicity of erythritol as a substrate. Caries Res 1992;26:358-362.

Khambanonda S, Chandravejjsmarn R, Barmes DE, Sardo Infirri J, Moller I: Prevention of dental caries in Thailand: 3 fluoridated products submitted for comparative tests. J Biol Buccale 1983;11:255-263.

Lingström P, Lundgren F, Birkhed D, Takazoe I, Frostell G: Effects of frequent mouthrinses with palatinose and xylitol on dental plaque. Eur J Oral Sci 1997; 105:162-169.

Machiulskiene V, Nyvad B, Baelum V: Caries preventive effect of sugar-substituted chewing gum. Community Dent Oral Epidemiol 2001; 29:278-288. 
Mäkinen KK, Benett CA, Hujoel PP, Isokangas PJ, Isotupa KP, Rape HR, Mäkinen P-L: Xylitol chewing gums and caries rates: A 40-month cohort study. J Dent Res 1995a;74:19041913.

Mäkinen KK, Hujoel PP, Benett CA, Isotupa KP, Mäkinen P-L, Allen P: Polyol chewing gums and caries rates in primary dentition: A 24 month cohort study. Caries Res 1996a;30:408417.

Mäkinen KK, Isotupa KP, Kivilompolo T, Mäkinen P-L, Murtomaa S, Petaja J, Toivanen J, Söderling E: The effect of polyol-combinant saliva stimulants on $S$. mutans levels in plaque and saliva of patients with mental retardation. Spec Care Dentist 2002;22:187-193.

Mäkinen KK, Isotupa KP, Kivilompolo T, Mäkinen P-L, Toivanen J, Söderling E: Comparison of erythritol and xylitol saliva stimulants in the control of dental plaque and mutans streptococci. Caries Res 2001;35:129-135.

Mäkinen KK, Mäkinen P-L, Pape HR Jr, Allen P, Benett CA, Isokangas PJ, Isotupa KP: Stabilisation of rampant caries: Polyol gums and arrest of dentine caries in two long-term cohort studies in young subjects. Int Dent J 1995b;45: 93-107.

Mäkinen KK, Pemberton D, Mäkinen P-L, Chen C-Y, Cole J, Hujoel PP, Lopatin D, Lambert P: Polyol-combinant saliva stimulants and oral health in Veterans Affairs patients - An exploratory study. Spec Care Dentist 1996b:16:104115.

Mäkinen KK, Söderling E, Isokangas P, Tenovuo J, Tiekso J: Oral biochemical status and depression of Streptococcus mutans in children during 24- to 36-month use of xylitol chewing gum. Caries Res 1989;23:261-267.

Manning RH, Edgar WM, Agalamanyi EA: Effects of chewing gums sweetened with sorbitol or a sorbitol/xylitol mixture on the remineralisation of human enamel lesions in situ. Caries Res 1992;26:104-109.

Møller IJ: Sorbitol containing chewing gum and its significance for caries prevention. Dtsch Zahnärztl Z 1977;32(suppl 1):66-70.

Møller IJ, Poulsen S: The effect of sorbitol-containing chewing gum on the incidence of dental caries, plaque and gingivitis in Danish schoolchildren. Community Dent Oral Epidemiol 1973; 1:58-67.
Petersen PE, Razanamihaja N: Carbamide-containing polyol chewing gum and prevention of dental caries in Madagascar. Int Dent J 1999; 49:226-230.

Rogers AH, Pilowsky KA, Zilm PS, Gully NJ: Effects of pulsing with xylitol on mixed continuous cultures of oral streptococci. Aust Dent J 1991;36:231-235.

Rosenhek M, MacPherson LMD, Dawes C: The effects of chewing-gum stick size and duration of chewing on salivary flow rate and sucrose and bicarbonate concentrations. Arch Oral Biol 1993;38:885-891.

Scheie AA, Fejerskov OB: Critical review - Xylitol in caries prevention: What is the evidence for clinical efficacy? Oral Dis 1998;4:268-278.

Scheie AA, Fejerskov OB, Danielsen B: The effect of xylitol-containing chewing gums on dental plaque and acidogenic potential. J Dent Res 1998;77:1547-1552.

Scheinin A, Mäkinen KK, Tammisalo E, Rekola M: Turku sugar studies. XVIII. Incidence of dental caries in relation to 1-year consumption of xylitol chewing gum. Acta Odontol Scand 1975a;33(suppl 70):307-316.

Scheinin A, Mäkinen KK, Ylitalo K: Turku sugar studies. V. Final report on the effect of sucrose, fructose and xylitol diets on caries incidence in man. Acta Odontol Scand 1975b;33(suppl 70):67-104.

Scheinin A, Pienihäkkinen K, Tiekso J, Banoczy J, Szoke J, Esztari I, Zimmermann P, Hadas E: Collaborative WHO xylitol field studies in Hungary. VII. Two-year caries incidence in 976 institutionalized children. Acta Odontol Scand 1985;43:381-387.

Slack GL, Millward E, Martin WJ: The effect of tablets stimulating salivary flow on the incidence of dental caries: A two-year clinical trial. Br Dent J 1964;116:105-108.

Söderling E, Alaräisänen L, Scheinin A, Mäkinen KK: Effect of xylitol and sorbitol on polysaccharide production by and adhesive properties of Streptococcus mutans. Caries Res 1987;21: 109-116.

Söderling E, Isokangas P, Pienihäkkinen K, Tenovuo J: Influence of maternal xylitol consumption on acquisition of mutans streptococci by infants. J Dent Res 2000;79:882-887.

Söderling E, Isokangas P, Tenovuo J, Mustakallio S, Mäkinen KK: Long-term xylitol consumption and mutans streptococci in plaque and saliva. Caries Res 1991;25:153-157.
Söderling E, Mäkinen KK, Chen CY, Pape HR Jr, Loesche W, Mäkinen PL: Effect of sorbitol, xylitol, and xylitol/sorbitol chewing gums on dental plaque. Caries Res 1989;23:378-384.

Söderling E, Trahan L, Tammialai-Salonen T, Häkkinen L: Effects of xylitol, xylitol-sorbitol, and placebo chewing gums on the plaque of habitual xylitol consumers. Eur J Oral Sci 1997;105: 170-177.

Szöke J, Bánóczy J, Proskin HM: Effect of aftermeal sucrose-free gum chewing on clinical caries. J Dent Res 2001;80:1725-1729.

Tanzer JM: Xylitol chewing gum and dental caries. Int Dent J 1995;45:65-76.

Tenovuo J, Hurme T, Ahola A, Svedberg C, Ostela I, Lenander-Lumikari M, Neva M: Release of cariostatic agents from a new buffering fluoride- and xylitol-containing lozenge to human whole saliva in vivo. J Oral Rehabil 1997;24: 325-331.

Thorild I, Lindau B, Twetman S: Effect of maternal use of chewing gums containing xylitol, chlorhexidine or fluoride on mutans streptococci colonization in the mothers' infant children. Oral Health Prev Dent 2003;1:53-57.

Topitsoglou V, Birkhed D, Larsson L-Å, Frostell G: Effect of chewing gums containing xylitol, sorbitol or a mixture of xylitol and sorbitol on plaque formation, $\mathrm{pH}$ changes and acid production in human dental plaque. Caries Res 1983;17:369-378.

Trahan L: Xylitol: A review of its action on mutans streptococci and dental plaque - Its clinical significance. Int Dent J 1995; 45:77-92.

Trahan L, Derling ES, Drean MF, Chevrier MC, Isokangas P: Effect of xylitol consumption on the plaque saliva distribution of mutans streptococci and the occurrence and long-term survival of xylitol resistant strains. J Dent Res 1992;71:1785-1791.

Vadeboncoeur C, Trahan L, Mouton C, Mayrand D: Effect of xylitol on the growth and glycolysis of acidogenic oral bacteria. J Dent Res 1983; 62:882-884.

Wåler SM, Rölla G: Effect of xylitol on dental plaque in vivo during carbohydrate challenge. Scand J Dent Res 1983;91:256-259.

Wennerholm K, Arends J, Birkhed D, Ruben J, Emilson CG, Dijkman AG: Effect of xylitol and sorbitol in chewing gums on mutans streptococci, plaque $\mathrm{pH}$ and mineral loss of enamel. Caries Res 1994;28:48-54. 